\title{
THE NOVEMBER MEETING IN SANTA BARBARA
}

The five hundred eighty-sixth meeting of the American Mathematical Society was held at the University of California, Santa Barbara, in Goleta, California, on Saturday, November 18, 1961. There were 133 registrants at this meeting, 117 of whom were members of the Society.

By invitation of the Committee to Select Hour Speakers for Far Western Sectional Meetings, Professor Henry Helson of the University of California, Berkeley, addressed the Society on New words about Dirichlet series. He was introduced by Professor Edwin Hewitt.

There were four sessions for contributed papers, with Dr. G. J. Culler, Professor R. S. Lehman, Dr. R. R. Phelps, and Professor J. L. Selfridge presiding.

Berkeley, California

R. S. Pierce,

Associate Secretary 